\title{
Genetic Diversity and Population Structure in Bryophyte With Facultative Nannandry
}

\author{
Annick S. Lang ${ }^{1}$, Thies Gehrmann ${ }^{2}$ and Nils Cronberg ${ }^{1 *}$ \\ 'Department of Biology, Lund University, Lund, Sweden, ${ }^{2}$ Biomedical Data Sciences, Leiden University Medical Center, \\ Leiden, Netherlands
}

Among plants, gender dimorphism occurs in about $10 \%$ of all angiosperms and more than $50 \%$ of all moss taxa, with dwarf males (DM) found exclusively in some unisexual mosses. In this study, we explore the role of male dwarfism as a reproductive strategy in the widespread acrocarpous moss Dicranum scoparium, which has facultative male dwarfism, having both dwarf males (DMs) and normal-sized males (NMs). We retrieved 119 SNP markers from transcriptomes which were used to genotype 403 samples from 11 sites at seven localities in southern Sweden. Our aims were to compare the genetic variability and genetic structure of sexually reproducing populations at different

OPEN ACCESS

Edited by:

Bernard Goffinet,

University of Connecticut,

United States

Reviewed by:

Alejandra Moreno-Letelier, National Autonomous University

of Mexico, Mexico

Olaf Werner

University of Murcia, Spain

*Correspondence:

Nils Cronberg

nils.cronberg@biol.lu.se

Specialty section:

This article was submitted to Plant Systematics and Evolution,

a section of the journal

Frontiers in Plant Science

Received: 04 December 2019

Accepted: 08 March 2021

Published: 07 April 2021

Citation:

Lang AS, Gehrmann T and Cronberg N (2021) Genetic Diversity and Population Structure in Bryophyte

With Facultative Nannandry.

Front. Plant Sci. 12:517547.

doi: 10.3389/fp/s.2021.517547 geographic levels (cushion, site, and locality) and compare in particular the relative contribution of females, dwarf males and normal-sized males to the observed genetic diversity. The numbers of DMs differed strongly between sites, but when present, they usually outnumbered both females and NMs. Low genetic differentiation was found at locality level. Genetic differentiation was strongest between cushions for females and NMs and within cushions for DMs indicating small scale structuring and sometimes inbreeding. NMs were more clonal than either DMs or females. Genetic diversity was similar between females and DMs, but lower for NMs. Two haplotypes were shared between females and DMs and one haplotype was shared between a DM and a NM. In conclusion, our results show that DMs and NMs play different roles in reproduction, inbreeding may occur at cushion level, but gene flow is high enough to prevent substantial genetic drift.

Keywords: SNP, sexual reproduction, genetic variation, spore dispersal, nannandry, moss (Musci)

\section{INTRODUCTION}

Unisexuality is usually associated with a certain degree of sexual dimorphism (Badyaev, 2002; Poissant et al., 2010). Evolution of size dimorphism can occur when males and females have distinct roles in reproduction and potentially different requirements, so that they are exposed to contrasting natural and/or sexual selection pressures (Badyaev, 2002; Isaac, 2005). For example, sexual size dimorphism with larger males is generally attributed to combat ability, dominance establishment and access to females for mating (e.g., McElligott et al., 2001; Isaac, 2005) and is

Abbreviations: NMs, normal-sized males; DMs, dwarf males; Sampled localities in Southern Sweden: Lu, Snogeröd Lunnerna; Ro, Röan; Mu, Munkarp; KH, Klöva Haller; SL, Skanörs Ljung; Da, Dalby; Bj, Bjärsjölagård. 
mostly found in mammals. Reversed sexual size dimorphism, with larger females, is found in many animals, particularly among invertebrates. It is explained as (1) a response of reduced malemale competition, (2) extreme niche differentiation between genders, or (3) may be the result of the "Ghiselin-Reiss smallmale hypothesis" (Blanckenhorn et al., 1995), in which selection favor small males because they require less energy and hence can invest more time in sexual activities. Male dwarfism, a form of extreme size dimorphism where male measure at most half of the size of females, is most common in marine taxa (Fairbairn et al., 2007) and in small organisms, such as invertebrates, fishes, algae, and bryophytes. It might occur when (4) the probability to encounter a sexual partner is low and the need to keep sexual partners nearby is high, as for example in the bone-eating marine worm Osedax or anglerfishes (Vollrath, 1998; Pietsch, 2005; Vrijenhoek et al., 2008; Rouse et al., 2015): in these cases males evolved into rudimentary creatures, which are permanently attached to a normal-sized female. In contrast to well-known examples from the animal kingdom, the evolution of sexual dimorphism in plants has been much less studied (Geber et al., 1999; Puixeu et al., 2019), although gender dimorphism occur in approximately 6-10\% of all angiosperms (Geber et al., 1999; Vamosi et al., 2003) and in more than half of all moss taxa (Vanderpoorten and Goffinet, 2009; Frey and Kürschner, 2011). Male dwarfism, also called nannandry, has evolved several times independently in unrelated moss families (Vanderpoorten and Goffinet, 2009; Hedenäs and Bisang, 2011) and can either be obligate or facultative, i.e., males growing only as dwarfs or occurring as normal-sized males as well.

Mosses and other bryophytes (liverworts and hornworts) share the trait of having a lifecycle dominated by the haploid gametophyte, the diploid sporophyte generation is initiated after sexual fertilization and remain connected to the maternal shoot throughout its short existence. Most mosses are capable of both asexual and sexual reproduction. Asexual reproduction is common in mosses, allowing clonal regeneration from gametophytic fragments or specialized vegetative diaspores (gemmae). Sexual reproduction depends on water for antherozoids (sperm cells) to swim to the archegonia (Cronberg et al., 2006a; Rydgren et al., 2006). Due to the water dependency, fertilization in unisexual moss species is hampered by drought and physical separation of males and females (Vanderpoorten and Goffinet, 2009; Hedenäs and Bisang, 2011). Asexual reproduction is significant for short-range colonization and maintenance of existing populations and genotypes (LaakaLindberg et al., 2003; Glime, 2007). Sexual reproduction is important for recombination during meiosis which takes place in the diploid sporophyte, for adaptability and maintenance of genetic diversity as well as for long-range dispersal through mostly wind-dispersed spores (Cronberg, 2000). A high realized gene flow is often assumed from molecular markers (Patiño and Vanderpoorten, 2018), but attempts to sow spores in natural environment have often failed (Mishler, 1988) and only few studies have been designed to actually reveal genetic variability and genetic population structures at local scales.

Nannandry is unique to mosses among land plants and appears to have evolved as a means to increase the fertilization efficiency by decreasing the separation distance between genders and thus increasing the number of available mating partners for a female (Moya-Laraño et al., 2002; Hedenäs and Bisang, 2011; Rosengren and Cronberg, 2014). Minute males, originating from wind-dispersed spores, grow epiphytically on a much larger female and remain attached during their (bi)annual lifecycle. The growth is reduced to a few leaves, but nevertheless they produce fertile sexual branches (perigonia). Several dwarf males can be found on a single female, usually clustering close to the female sexual branches (perichaetia). Whereas the gender is controlled by sex chromosomes, empirical studies have demonstrated that the growth form of males (dwarfed or normalsized) could either be genetically determined (in species with obligate dwarf males) or controlled by the supporting female (Glime and Bisang, 2017 and reference therein).

If females in a nannandric species are predominantly fertilized by dwarf-males we can expect that the system is driven toward higher specialization for nannandry (e.g., smaller male spore sizes, with higher dispersal capacity at the expense of lower potential to germinate in the normal substrate) and eventually obligate nannandry. In a species with facultative nannandry, a dwarf male transmits its genes during one season, whereas a normal-sized male can transmit its genes over many years in the same patch and hence could slow down adaptation. However, if normal-sized males and dwarf-males are equally frequently fertilizing the females, the system may stay in a facultatively nannandric condition, without drift toward obligate nannandry. The relative frequency of dwarf males and normal-sized males and their associated haplotypic networks is therefore a key for understanding the development of a nannandric species.

Recent ecological and genetical studies of the nannandric species Homalothecium lutescens (Hedw.) H. Rob. have greatly extended our knowledge about nannandry in bryophytes (Rosengren et al., 2013, 2015, 2016). This species is pleurocarpous, having sporophytes on short lateral branches and forming loose and patchy colonies on calcareous ground. Recruitment of dwarf males takes place within colonies, sometimes leading to extreme inbreeding, but the studies also revealed that gene flow occurs between colonies within a population and even from external populations, frequently enough to maintain genetic variability and to prevent substantial genetic drift at population level. The fact that $H$. lutescens is almost completely obligately nannandrous has important implications for its population dynamics; dwarf males are sensitive to environmental factors such as drought, which may cause them to go extinct from time to time in local patches, while the females are more strongly clonal and persistent. This means that females follow a repeated recruitment model (sensu Eriksson, 1989, 1993) with perennial, highly clonal patches, whereas the DMs follow a metapopulation recruitment model (sensu Levins, 1969), having annual, nonpersistent individuals with strong fluctuation in numbers between years.

The genus Dicranum is unrelated to Homalothecium, belonging to the acrocarpous moss groups, characterized by apical sporophytes on erect sparsely branched shoots and 
growth in dense tufts, radially expanding through vegetative proliferation. About half of the 131 Dicranum species reproduce only asexually, amongst the sexually reproducing species, 21 lack dwarf males and 25 are reported as nannandric, only two of which, Dicranum scoparium Hedw. and Dicranum bonjeanii De Not., have facultative dwarfism (Pichonet and Gradstein, 2012). In this study we focus on the widespread species D. scoparium sampled from seven localities, using 90 single-nucleotide polymorphic markers (SNPs). Our overall aims are to employ the molecular markers in a moss with facultative nannandry in order to (1) reveal the hierarchical genetic population structure (2) determine if the levels of genetic diversity and clonality compare between females and males and (3) assess the relative shares of dwarf males and normal-sized males to the total standing genetic diversity.

\section{MATERIALS AND METHODS}

\section{Study Species}

Dicranum scoparium is widely distributed in the Holarctic and is growing on various substrates, preferably on acidic soil, rotten logs, tree stems and sometimes in sympatry with other Dicranum species (Crum and Anderson, 1981; Hedenäs and Bisang, 2004; Ireland, 2007; Lang et al., 2014). Both normal-sized and dwarf males can occur simultaneously in a same cushion. Dwarf males are annual and are easily found in the late summer on the tomentum of a female stem that carries a young sporophyte. They are supposedly non-clonal, whereas the perennial normal-sized males are clonal, resembling the females and, if present, found in the external part of a cushion.

\section{Sample Collection}

Fresh bryophyte material was collected in August 2015 across Skåne, South Sweden. In total 54 fertile cushions (including two cushions of $D$. bonjeanii and five of Dicranum majus) from 11 sites were collected from seven different localities, namely Snogeröd Lunnerna (Lu), Röan (Ro), Munkarp ( $\mathrm{Mu}$ ), Klöva Haller (KH), Skanörs Ljung (SL), Dalby (Da), Bjärsjölagård (Bj; Figure 1). In each of these localities, between one and three sites (if possible) were sampled. Two sites were considered distinct if they were separated from at least $2 \mathrm{~km}$ and by a river, road or ravine. Sexually reproducing populations are easily recognized in the field due to the presence of sporophytes and are generally associated with the presence of dwarf males and/or normal-sized males (Pichonet and Gradstein, 2012, pers. observ.). To perform genetic diversity analyses, we collected about $3 \mathrm{~cm}^{2}$ of Dicranum moss from sexually reproducing cushion. From each of these cushions, five fertile female stems were sampled. A stem can have several branches. Each of these branches were extracted separately as they also carried distinct sporophytes. Therefore, the number of female samples genotyped and then analyzed is bigger than five. All dwarf males found of on theses female stems were separated for in vitro growth and all normal-sized males within each of these cushions were sampled. The collected material was kept alive in the experimental garden of Lund University for morphological identification, resampling (if necessary), and further observation of vegetative growth.

\section{In vitro Culture of Dwarf Males}

In order to get sufficient amounts of DNA or RNA from a single dwarf male individual we induced vegetative growth by separating them from the female and placing them onto a nutrient agar medium. Here, we used a medium as described in Rudolph et al. (1988). Each male was carefully removed from the female tomentum using a dissecting microscope and thoroughly inspected for contaminants before plating. The number of males found in each locality varied greatly, from only three males found in one cushion from Lunnerna to 384 found among the cushions from Bjärsjölagård. In order to remove bacterial, fungal or algal contamination, clean parts of the newly grown gametophyte were replated in new petri dishes regularly during a year after cleaning treatment. This treatment involved soaking the gametophyte in a solution of $0.05 \%$ NADCC at constant shaking for $1 \mathrm{~min}$ followed by two rinses, each $1 \mathrm{~min}$ in demineralized water. Removal of contamination remained the most difficult problem because males did not always survive the replating process. For example, 92 out of 526 dwarf males from Bj and only 2 out of 51 DM from Da survived. Hence, out of more than 500 dwarf males initially cultured, only 140 dwarf males were subject to DNA extraction (Supplementary Appendix 1).

\section{DNA Extraction}

Total DNA from 769 samples including females, sporophytes, dwarf, and normal-sized males was extracted. Prior to extraction, stems of females, and normal-sized males were cleaned in demineralized water. After removing the surplus water with a tissue, all stems, sporophytes were placed in separate microtubes and kept in $\mathrm{a}-80^{\circ} \mathrm{C}$ freezer until extraction. After cultivation, dwarf males and associated protonemas were removed from the agar plates and dried in silica gel until extraction. DNA extractions were done using DNeasy Plant mini kit (Qiagen, Hilden, Germany) according to the protocol of the manufacturer and eluted in $100 \mu \mathrm{l} \mathrm{AE}$ buffer. All DNA extracts were stored at $-20^{\circ} \mathrm{C}$.

\section{RNA Extraction}

We applied a strategy involving transcriptome analyses for selection of SNP markers, which requires RNA extracts of high quality and quantity. Fresh plant material was used for RNA extraction and one female stem per locality was randomly sampled in order to represent the genetic variability of the population. Three additional extraction was done for pooled normal-sized males, sporophytes (diploid generation) and one Dicranum majus Turner female gametophyte. Each stem was first cleaned in deionized water and then flash frozen in liquid nitrogen before being stored at $-80^{\circ} \mathrm{C}$. Consequently, RNA from ten samples were obtained using the RNeasy Plant mini kit following the protocol of the manufacturer (Qiagen, Hilden, Germany). The quality, quantity and integrity of the RNA extractions were measured on agarose gels, with Qubit ${ }^{\circledR}$ 2.0 fluorometer (Thermo Fisher Scientific, Waltham, MA, 


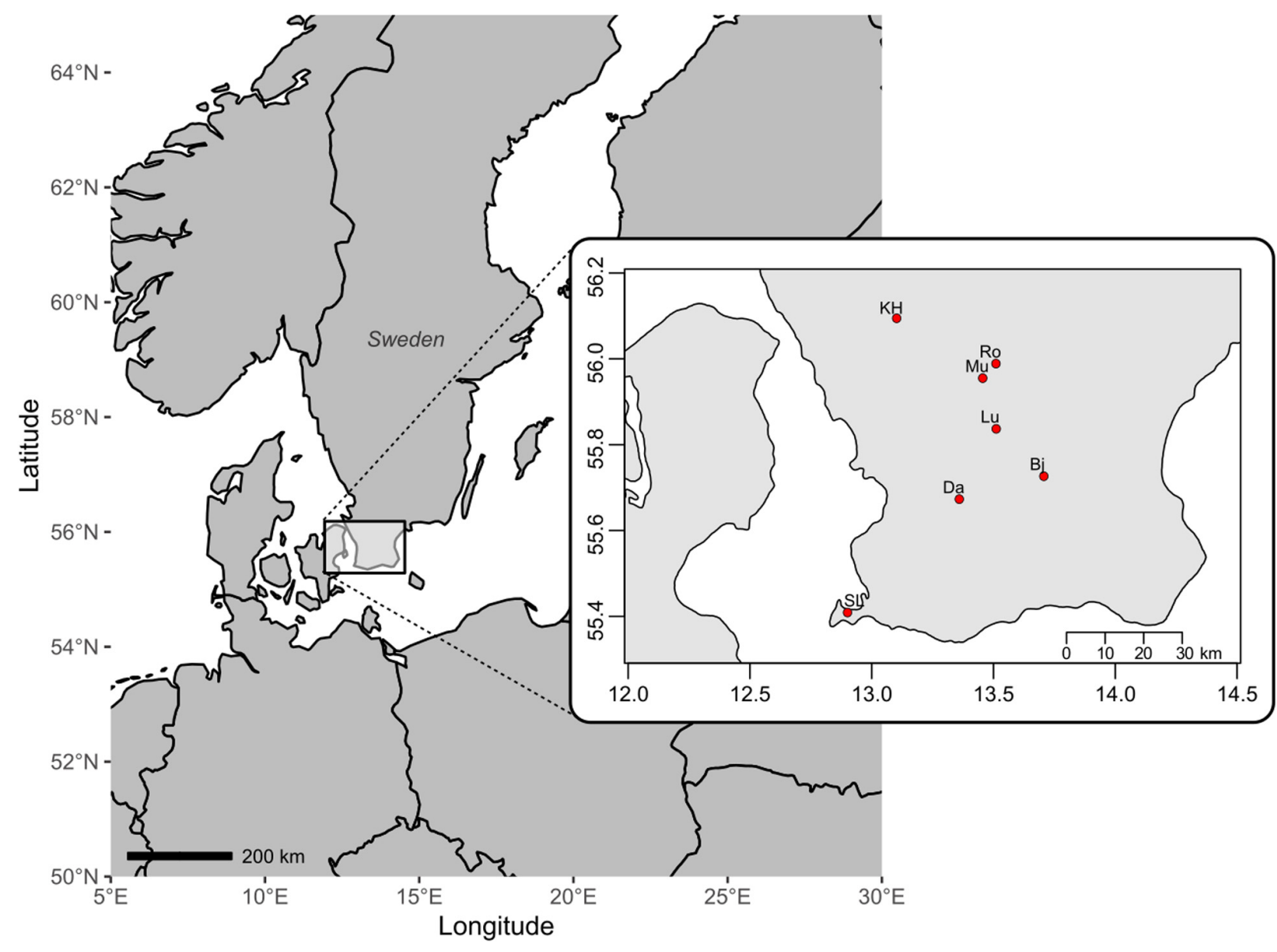

FIGURE 1 | Map of southern Sweden with seven localities where populations of the moss Dicranum scoparium have been sampled: Bj, Bjärsjölagård; Da, Dalby; KH, Klöva Haller; Lu, Snogeröd Lunnerna; Mu, Munkarp; Ro, Röan; SL, Skanörs Ljung.

United States) and BioAnalyzer (Agilent Technologies, Palo Alto, CA, United States), respectively.

\section{SNP Localization, Typification and Genotyping}

The SNP library was produced with the MiSeq system (Illumina, United States) using the 300 bp paired-end settings. The library construction was carried out at Lund University sequencing facility $^{1}$ using NEXTflex RNA-Seq kit (Bioo Scientific, Austin, TX, United States).

The sequencing of the moss transcriptomes resulted in about 1 million reads/sample (Supplementary Appendix 2). The sample DaF was used to create a De Novo reference assembly using Trinity (Grabherr et al., 2011; Haas et al., 2013). Reads from other samples were realigned using BOWTIE (Langmead et al., 2009) with -m option, allowing no multialigned reads in order to reduce as much as possible false positive SNP calling. We use the samtools (Li et al., 2009) mpileup tool to produce VCF files with all single nucleotide variants in the aligned BAM files. In

${ }^{1}$ https://www.biology.lu.se/services/dna-sequencing-facility/next-generationsequencing-on-illumina-miseq total, nearly 25,000 variants were found. SNP filtering was done using scripts specifically designed for this purpose ${ }^{2}$. To remove variants called due to indel alignments, we removed SNPs within $100 \mathrm{bp}$ of each other. To further support the authenticity of the variants, we selected only variants which were identified in at least three individuals. This also removes rare variants which are not useful in a genetic diversity screening (most variants are rare variants). Finally, to ensure the variants were still adequate markers of genetic diversity, we removed variants which were present in more than 8 (out of 10) samples. This resulted in a final selection of 119 SNPs.

The genotyping of 738 DNA samples was carried out at the SNP\&SEQ Technology Platform, Department of Medical Sciences of Uppsala University. It was performed using a multiplexed primer extension chemistry of the iPLEX assay (Ross et al., 1998; Storm et al., 2003; Gabriel et al., 2009). The allele was then detected by mass spectrometry with a MassARRAY analyzer (Agena Bioscience, Hamburg, Germany). Raw data was converted to genotype data using Typer software (Agena Bioscience).

\footnotetext{
${ }^{2}$ https://github.com/thiesgehrmann/annickMossVarCall
} 


\section{SNP Data Analyses}

The analyses were performed on D. scoparium individuals only, excluding sporophytes data. The final number of individuals analyzed in this study is found in Table 1. In order to analyze female and male genotypic diversity, or haplotypic diversity in this case, as well as levels of clonality within populations, we selected all gametophytic data from the raw SNP dataset (GAM). Then, because genet recruitment of female, normalsized males, and nannandrous males was expected to follow different recruitment models, two subsets were created according to the sex of the samples, i.e., one subset containing female data (FEM) and one with male data (males). Additionally, to estimate the genetic differentiation within the two male types, dwarf males (DMs) and normal-sized males (NMs) were also analyzed separately. All analyses were performed in R ( $\mathrm{R}$ Development Core Team, 2013) and genetic diversity metrics as well as levels of clonality within each population were characterized using the packages adegenet version 2.1.2 (Jombart, 2008; Jombart and Ahmed, 2011), poppr v. 2.8 .5 (Kamvar et al., 2014, 2015), and ade4 v. 1.7-15 (Chessel et al., 2004; Dray and Dufour, 2007; Dray et al., 2007; Bougeard and Dray, 2018). The analyses were performed with population hierarchy that included two levels, i.e., locality and cushion. Implementation and interpretation of poppr outputs were adapted from http://grunwaldlab.github.io/ Population_Genetics_in_R/ (Grünwald et al., 2017).

Firstly, failed genotyped individuals and SNPs were excluded from the raw data set. Then, the different subsets were created. Individuals and SNPs containing more than 10\% missing information, invariable and uninformative loci (minimum allele frequency of 0.01) independently for each subset were excluded. Finally, we controlled again that the data set would contain no more than $10 \%$ missing information and eventually remove the individual or SNP that would not meet the criteria.

To remove the effect of genetic linkage due to clones and adjust for missing data and genotyping errors that may occur during sequencing large datasets (c.f. Kamvar et al., 2015), multilocus lineages (MLL) were calculated with the mlg.filter function by collapsing unique MLH (multilocus haplotypes) utilizing Nei genetic distance given the farthest neighbor clustering algorithm. This method allows to incorporate genotypes that have missing

TABLE 1 | Summary of the D. scoparium dataset showing sample size, number of haplotypes and codominant loci for each data subset after passing all filtering criteria.

\begin{tabular}{lcccc}
\hline Dataset & $\boldsymbol{n}$ & Loci & MLH & MLL \\
\hline GAM & 403 & 68 & 258 & 148 \\
FEM & 211 & 64 & 107 & 61 \\
males & 192 & 74 & 148 & 90 \\
DM & 134 & 74 & 113 & 72 \\
NM & 57 & 61 & 25 & 14 \\
\hline
\end{tabular}

Ten percentage or more missing data as well as invariable and uninformative loci were excluded for each data set independently. n, number of individuals; Loci, number loci; $M L H$, number of multilocus haplotype; MLL, number of multilocus lineages obtained after collapsing of unique $M L H$. Numbers are given for the total dataset (GAM) and the female (FEM), male (males) dwarf males (DM), and normal sized (NM) subsets. data or genotyping error into a parent clusters. The clustering threshold was set for each dataset individually and missing data were replaced with the mean of the alleles for the entire data set.

Multilocus lineages were further used for the estimation of the haplotypic diversity (G; Stoddart and Taylor, 1988) and Nei's gene diversity, also called unbiased gene diversity ( $\hat{\mathrm{h}}$; cf. Grünwald and Hoheisel, 2006). Furthermore, the relative contribution of clonality within a population was assessed by using the index of association (IA) and its standardized form, $\overline{\mathrm{r}}_{d}$, which accounts for the number of loci sampled (Agapow and Burt, 2001). Considering that IA is based on the variance of pairwise distances between MLLs, IA should be high in clonal populations and low in populations undergoing sexual reproduction (Grünwald and Hoheisel, 2006). A significance test with 1000 permutations was run to assess for significance. Hierarchical structure of genetic variation was explored by running an analysis of molecular variance [AMOVA (Excoffier et al., 1992)] considering cushion as subpopulations within localities. The analysis was conducted using the poppr.amova function and the ade4 implementation. Fixation indices ( $\Phi$ statistics) were interpreted as a measure of subpopulation differentiation. The probability of retrieving the observed $\Phi$ under the null hypothesis of no differentiation between subpopulations was calculated using the randtest function of the ade4 package with 1000 iterations of the permutation test.

Assuming that the diversity of DM haplotypes residing on a female is determined by the number male spores that germinated on the female, the proportion of DMs should covary with haplotypic diversity in a population. Therefore, the proportion of each sex type at locality was plotted against the haplotypic diversity G. Kruskal Wallis non-parametric test was used to examine the differences in $G$ between sex types. Furthermore, an ANOVA was used to test for the differences of $\hat{h}$ between sex types as residuals followed a normal distribution. We also compared Nei's gene diversity $\hat{h}$ against $G$ in order to display the contribution of each haplotype to the total variability at cushion level.

Finally, population structure was analyzed in two ways. First, a principal coordinate analysis (PCoA) was performed on female and male individuals. The analysis was based on a pairwise genetic distance matrix, with Prevosti's distance, equivalent to dissimilarity distance. Then, a minimum-length spanning network (msn) of all unique MLL was constructed based on the Prevosti's distance in order to assess how female and male haplotypes were related across different populations. Resulting graphs were edited with Inkscape v.1.0.0.

\section{RESULTS}

\section{SNP Detection in RNA and DNA Genotypification}

From the 10 initial samples, 119 SNPs were identified for genotype screening (see section "Materials and Methods"). Out of 769 extracted DNA samples, 738 were suitable for genotyping, whereas 31 lacked enough DNA for genotyping. Of the 119 
SNPs, 90 SNP markers were identified in all 738 genotyped DNA samples. The fraction of SNP markers with call rate $>0$ reached $75.63 \%$ and the average sample call rate per SNP reached $88.49 \%$. The fraction of individuals with call rate $>0$ reached $95.80 \%$ while the average SNP call rate per sample reached $69.86 \%$. Five out of 90 SNPs were invariable (5.56\%). The 29 deficient SNPs had no allele signal cluster separation (sample call rate of $0 \%$ ) which resulted in inaccurate genotype calls.

\section{Higher Genetic Diversity Among Females and Dwarf Males Than Among Normal-Sized Males}

After exclusion of individuals and SNPs with $10 \%$ or more missing data and invariable loci, the total D. scoparium haploid dataset contained 403 individuals and 68 loci (Table 1). The proportions of males (NMs and DMs) and females reflect the frequencies at each site. Five sites had both NMs and DMs, three had only NMs and two only DMs (Table 2). The number of DMs differed strongly between sites, and when present, they usually outnumbered both females and $\mathrm{NMs}$, and at one site (Bj), they were particularly abundant (Table 2). The female dataset was composed of 211 individuals and 64 loci, representing 61 MLLs. The male dataset contained 192 individuals and 74 loci, representing 90 MLLs (Table 1).

Multilocus haplotypic diversity (G) differed between localities, from $G=5.45$ in Dalby to $G=18.39$ in Bjärsjölagård and the underlying proportions of female, NM and DM haplotypes were profoundly disparate. The NMs had significantly lower haplotypic diversity (mean $G=1.8$ ) than both females (mean $G=6.9$ ) and DMs (mean $G=8.2$ ) (Kruskal-Wallis; $H=6.8 ; \mathrm{df}=2$; $P=0.03$ ). Furthermore, the haplotypic diversity for DMs varied a lot dependent on the number of individuals that were possible to

TABLE 2 | Number of $D$. scoparium individuals in each data subset used for the analysis after passing all filtering criteria.

\begin{tabular}{lccccc}
\hline Locality & Site & Cushion & FEM & DM & NM \\
\hline $\mathrm{Bj}$ & 1 & 3 & $21(2)$ & $88(43)$ & 0 \\
$\mathrm{Da}$ & 1 & 4 & $19(5)$ & $2(2)$ & $2(1)$ \\
$\mathrm{KH}$ & 1 & 4 & $18(8)$ & 0 & $10(2)$ \\
$\mathrm{KH}$ & 2 & 6 & $15(6)$ & 0 & $1(1)$ \\
$\mathrm{Lu}$ & 1 & 3 & $7(4)$ & $3(1)$ & $2(1)$ \\
$\mathrm{Lu}$ & 2 & 1 & $5(1)$ & 0 & 0 \\
$\mathrm{Lu}$ & 3 & 2 & $9(6)$ & 0 & $2(2)$ \\
$\mathrm{Mu}$ & 1 & 8 & $30(9)$ & $4(3)$ & $8(3)$ \\
$\mathrm{Ro}$ & 1 & 5 & $23(6)$ & $25(17)$ & $8(2)$ \\
$\mathrm{Ro}$ & 2 & 5 & $18(6)$ & $6(2)$ & 0 \\
$\mathrm{SL}$ & 1 & 6 & $46(9)$ & $6(5)$ & $24(3)$ \\
Total & 16 & 47 & $211(61)$ & $134(72)$ & $57(15)$ \\
\end{tabular}

The localities are Bj, Bjärsjölagård; Da, Dalby; KH, Klöva Haller; Lu, Snogeröd Lunnerna; Mu, Munkarp; Ro, Röan; SL, Skanörs Ljung. Numbers in parenthesis are the number of unique multilocus lineage, corresponding to the number of individuals with unique haplotype. Site, site number within the locality; Cushion, number of cushions within each site; FEM, number of females; DM, number of dwarf males; NM, number of normal-sized males.
TABLE 3 | Genetic diversity at locality level for the combined dataset (GAM), female (FEM), dwarf male (DM), normal-sized male (NM), and all male (males) data subsets.

\begin{tabular}{|c|c|c|c|c|c|c|c|c|}
\hline Locality & & $n$ & MLH & MLL & G & $\hat{\mathrm{h}}$ & IA & $\overline{\mathbf{r}}_{d}$ \\
\hline \multirow[t]{5}{*}{$\mathrm{Bj}$} & GAM & 110 & 80 & 49 & 18.39 & 0.19 & 8.44 & 0.18 \\
\hline & FEM & 21 & 8 & 2 & 1.57 & 0.16 & 26.19 & 0.97 \\
\hline & males & 89 & 74 & 49 & 32.07 & 0.19 & 6.8 & 0.13 \\
\hline & $\mathrm{DM}$ & 88 & 76 & 43 & 26.34 & 0.2 & 7.61 & 0.14 \\
\hline & NM & 0 & & & & & & \\
\hline \multirow[t]{5}{*}{$\mathrm{Da}$} & GAM & 23 & 15 & 8 & 5.45 & 0.31 & 6.78 & 0.14 \\
\hline & FEM & 19 & 9 & 5 & 3.97 & 0.29 & 8.88 & 0.21 \\
\hline & males & 4 & 4 & 3 & 2.67 & 0.31 & 8.77 & 0.22 \\
\hline & $\mathrm{DM}$ & 2 & 2 & 2 & 2 & 0.4 & NA & $N A$ \\
\hline & NM & 2 & 2 & 1 & 1 & 0 & NA & NA \\
\hline \multirow[t]{5}{*}{$\mathrm{KH}$} & GAM & 44 & 30 & 17 & 11.13 & 0.33 & 2.71 & 0.04 \\
\hline & FEM & 33 & 18 & 14 & 10.37 & 0.33 & 2.46 & 0.04 \\
\hline & males & 11 & 7 & 3 & 1.75 & 0.17 & 20.14 & 0.52 \\
\hline & $\mathrm{DM}$ & 0 & & & & & & \\
\hline & NM & 11 & 5 & 3 & 1.75 & 0.19 & 19.4 & 0.53 \\
\hline \multirow[t]{5}{*}{ Lu } & GAM & 28 & 17 & 13 & 7.84 & 0.34 & 7.03 & 0.13 \\
\hline & FEM & 21 & 11 & 10 & 6.04 & 0.34 & 7.59 & 0.15 \\
\hline & males & 7 & 5 & 3 & 1.81 & 0.21 & 22.65 & 0.6 \\
\hline & $\mathrm{DM}$ & 3 & 2 & 1 & 1 & 0 & NA & NA \\
\hline & NM & 4 & 4 & 3 & 2.67 & 0.35 & 11.57 & 0.33 \\
\hline \multirow[t]{5}{*}{$\mathrm{Mu}$} & GAM & 42 & 30 & 14 & 10.63 & 0.32 & 3.4 & 0.06 \\
\hline & FEM & 30 & 21 & 9 & 8.18 & 0.31 & 3.45 & 0.07 \\
\hline & males & 12 & 9 & 5 & 2.57 & 0.2 & 14.12 & 0.29 \\
\hline & $\mathrm{DM}$ & 4 & 4 & 3 & 2.67 & 0.28 & 17.47 & 0.47 \\
\hline & NM & 8 & 3 & 3 & 1.68 & 0.09 & 19.16 & 0.96 \\
\hline \multirow[t]{5}{*}{ Ro } & GAM & 80 & 51 & 32 & 19.05 & 0.36 & 2.68 & 0.05 \\
\hline & FEM & 41 & 24 & 12 & 10.44 & 0.35 & 3.1 & 0.06 \\
\hline & males & 39 & 28 & 21 & 12.17 & 0.32 & 4.27 & 0.07 \\
\hline & $\mathrm{DM}$ & 31 & 23 & 19 & 12.81 & 0.32 & 5.21 & 0.09 \\
\hline & NM & 8 & 3 & 2 & 1.28 & 0.08 & 18.82 & 0.99 \\
\hline \multirow[t]{5}{*}{ SL } & GAM & 76 & 35 & 16 & 9.66 & 0.35 & 4.56 & 0.07 \\
\hline & FEM & 46 & 16 & 9 & 7.45 & 0.37 & 5.43 & 0.09 \\
\hline & males & 30 & 21 & 7 & 2.87 & 0.24 & 14.06 & 0.3 \\
\hline & $\mathrm{DM}$ & 6 & 6 & 5 & 4.5 & 0.24 & 9.38 & 0.24 \\
\hline & NM & 24 & 8 & 3 & 2.27 & 0.18 & 21.13 & 0.92 \\
\hline \multirow[t]{5}{*}{ Average } & GAM & & & & 11.74 & 0.31 & & \\
\hline & FEM & & & & 6.86 & 0.31 & & \\
\hline & males & & & & 7.99 & 0.23 & & \\
\hline & $\mathrm{DM}$ & & & & 7.05 & 0.24 & & \\
\hline & NM & & & & 1.68 & 0.15 & & \\
\hline
\end{tabular}

$n$, sample size; $M L H$, Multilocus haplotype; $M L L$, Multilocus lineages; $G$, Haplotypic diversity based on Stoddard and Taylor's index; $\hat{h}$, Nei's unbiased gene diversity; $I A$, index of association; $\bar{r}_{d}$, Standardized IA. All $\hat{h}$ and IA values were significant $(P<0.001)$, based on 1,000 permutations.

genotype (mean $G=8.2$; Table 3). Although the different sample sizes explain some of the variation in G, Figure $\mathbf{2 A}$ illustrates that the proportion of females or NMs in a population had low influence on haplotypic diversity and that only the proportion of DMs correlated with haplotypic diversity $\left(R^{2}=0.98\right)$, although this is largely due to two localities with abundant population of dwarf males ( $\mathrm{Bj}$ and Ro). 

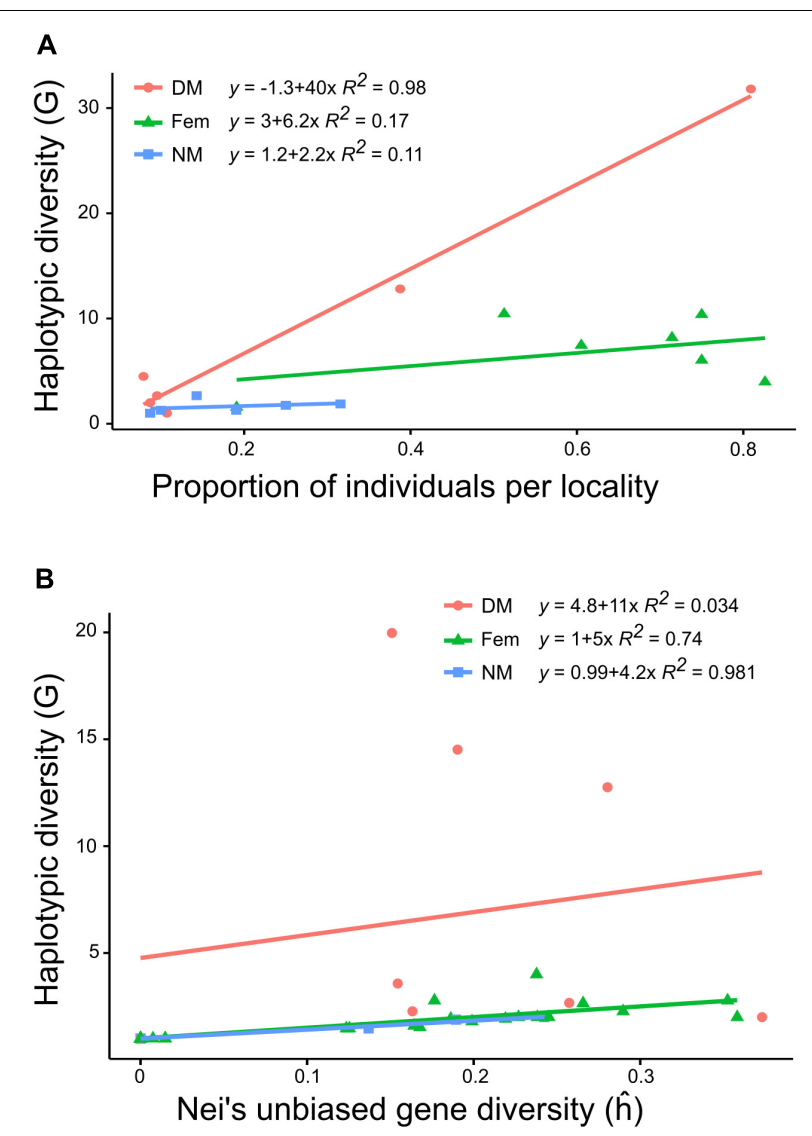

FIGURE 2 | Scatter plot with regression lines and $R^{2}$ showing (A) the proportion of individuals at locality level against the genotypic diversity $(G)$ and (B) the expected gene diversity ( $\hat{h}$ ) against $G$ for each sex type (dwarf males, females, and normal-sized males). Colors of regression line and point represent sex types (red dot, dwarf males; Green triangle, females; Blue square, normal-sized males).
Overall, levels of gene diversity $\hat{h}$ were slightly higher for females (mean $\hat{\mathrm{h}}=0.31$ ) than males (mean $\hat{\mathrm{h}}=0.23$ ) (ANOVA; $F=4.83 ; P=0.048)$. The DMs (mean $\hat{\mathrm{h}}=0.24$ ) were usually more variable than the NMs (mean $\hat{\mathrm{h}}=0.15$ ) and NMs had significantly lower gene diversity than both females and DMs (ANOVA; $F=4.22 ; P=0.03$ ). In most localities NMs had $\hat{\mathrm{h}}$ values ranging between 0 and 0.19 , but one exception was found at $\mathrm{Lu}$, with $\hat{\mathrm{h}}=0.34$ for both females and NMs (Table 3). At cushion level, which is the scale relevant for fertilization, gene diversity was strongly positively correlated with haplotypic diversity, except at patches with numerous DMs (Figure 2B). This means that each normal-sized haplotype contributes about equally much to the total genetic variability at cushion level. The cushion level estimate of $\hat{\mathrm{h}}$ is equal or higher for DMs as compared to NMs, but the variation is potentially distributed among many more haplotypes for DMs.

The degree of clonality was measured with the index of association (IA). Clonality was strongest for NMs at all localities, with high IA values and $\overline{\mathrm{r}}_{d}$ values ranging between 0.32 and 1 , suggesting high clonality. As expected, DMs had $\bar{r}_{d}$ values close to 0 , which indicate low clonality but somewhat surprisingly, female IA and $\vec{r}_{d}$ values were similar to those obtained for DMs. The populations in Bj showed an opposite pattern: levels of haplotypic diversity were very low for females and very high for males, although levels of gene diversity were comparable. Furthermore, IA and $\overline{\mathrm{r}}_{d}$ values indicated high clonality of females at this locality.

\section{Population Structure}

Almost $90 \%$ of the total variation was partitioned nearly equally within cushions and among cushions within localities, while only $11 \%$ of the variation occurred among localities (Table 4 : GAM). $25 \%$ of the molecular variance was associated with a differentiation within female cushions (haplotypes among localities) and $68 \%$ with differentiation among cushions within localities (haplotypes among cushions within localities). Males also displayed a high relative differentiation at cushion level ( $\mathrm{DM}=47.1 \%$ and $\mathrm{NM}=30 \%$, respectively). The highest fixation index was within cushions in both females and NMs (FEM: $\Phi=0.75$; NM: $\Phi=0.7$ ).

A PCoA was produced to visualize the genetic distance of female and male individuals (Figure 3). Overall, the low differentiation among the female samples at locality levels observed in the AMOVA analyses was reflected in the PCoAs. The first three axes explained $16.25 \%$ of cumulative variation (PC1: 7.12\%, PC2: $4.76 \%$, and PC3: 4.37\%). No clear subclustering was displayed, only few individuals from $\mathrm{Bj}$ were forming a separate cluster, best separated by PC1 and PC3. However, looking at locality with more than one site individually ( $\mathrm{Lu}, \mathrm{Ro}$ ), some fine structure could be seen. In population Lu (black shapes), site 1 and 3 were forming two clusters with certain degree of overlapping and site 2 was more distant from the two former. Ro had two sites (red empty shapes) which were separated by PC1 and PC2. Although SL had only one site, the individuals were forming two clusters separated by PC2.

The first three axes of the male PCoA explained 28.13\% cumulative variance (PC1: 15.13\%, PC2: 7.32\%, and PC3: 5.68\%). Similar to the females, the male PCoA displayed little structure at locality level (Figure 4), except for Bj. Most individuals (all dwarf males) of this locality were separated by PC1 from all other individuals, all localities included. Whereas no differentiation could be revealed at site level, more structure was observed at the sex level, i.e., between normal-sized males (NM, big shapes) and dwarf males (DM, small shapes). NMs from a certain site tended to cluster more closely, being more similar to each other than DMs. PC2 segregated strongly the individuals in SL 1 into three clusters, two containing only NMs and one containing only DMs (purple triangles). Furthermore, individuals from Lu 1 (black triangles) were strongly separated from the individuals from $\mathrm{Lu}$ 3. Finally, PC3 tended to segregate individuals from $\mathrm{KH} 1$ and 2, Lu 1 and 3 as well as DMs and NMs from Ro 1.

To visualize relationships between female and male MLLs, a minimum-spanning network was constructed (Figure 5). The number of individuals per MLL (or haplotype) ranged between 1 and 16. Sixty-one female MLLs, 13 NM MLLs, and 77 DM MLLs were having more than one individual of which 7,1 , and 2 MLLs for female, NM and DM, respectively, where shared between 
TABLE 4 | Analysis of molecular variance (AMOVA).

\begin{tabular}{|c|c|c|c|c|c|c|c|}
\hline Dataset & Hierarchical level & Df & Sum of squares & Mean squares & Variation (\%) & $\Phi$ & $P$ \\
\hline GAM & $\Phi$ among cushion within locality & 40 & 3837.14 & 95.93 & 45.92 & 0.52 & 0.001 \\
\hline \multirow[t]{3}{*}{ FEM } & $\Phi$ within cushion & 164 & 1022.13 & 6.23 & 25.3 & 0.75 & 0.001 \\
\hline & $\Phi$ among cushion within locality & 40 & 3130.33 & 78.26 & 68.27 & 0.73 & 0.001 \\
\hline & $\Phi$ among locality & 6 & 890.44 & 148.41 & 6.43 & 0.06 & 0.001 \\
\hline \multirow{2}{*}{ DM } & $\Phi$ among cushion within locality & 5 & 386.62 & 77.32 & 19.8 & 0.3 & 0.001 \\
\hline & $\Phi$ among locality & 5 & 950.75 & 190.15 & 33.06 & 0.33 & 0.040 \\
\hline \multirow[t]{3}{*}{ NM } & $\Phi$ within cushion & 46 & 338.72 & 7.36 & 30.01 & 0.7 & 0.001 \\
\hline & $\Phi$ among cushion within locality & 5 & 145.02 & 29 & 50.01 & 0.62 & 0.003 \\
\hline & $\Phi$ among locality & 5 & 667.47 & 133.49 & 19.98 & 0.2 & 0.004 \\
\hline
\end{tabular}

AMOVA results for combined data (GAM), female (FEM), dwarf males (DM), and normal-sized males (NM). $P$ values were obtained for the $\Phi$ statistic with 1000 permutations.

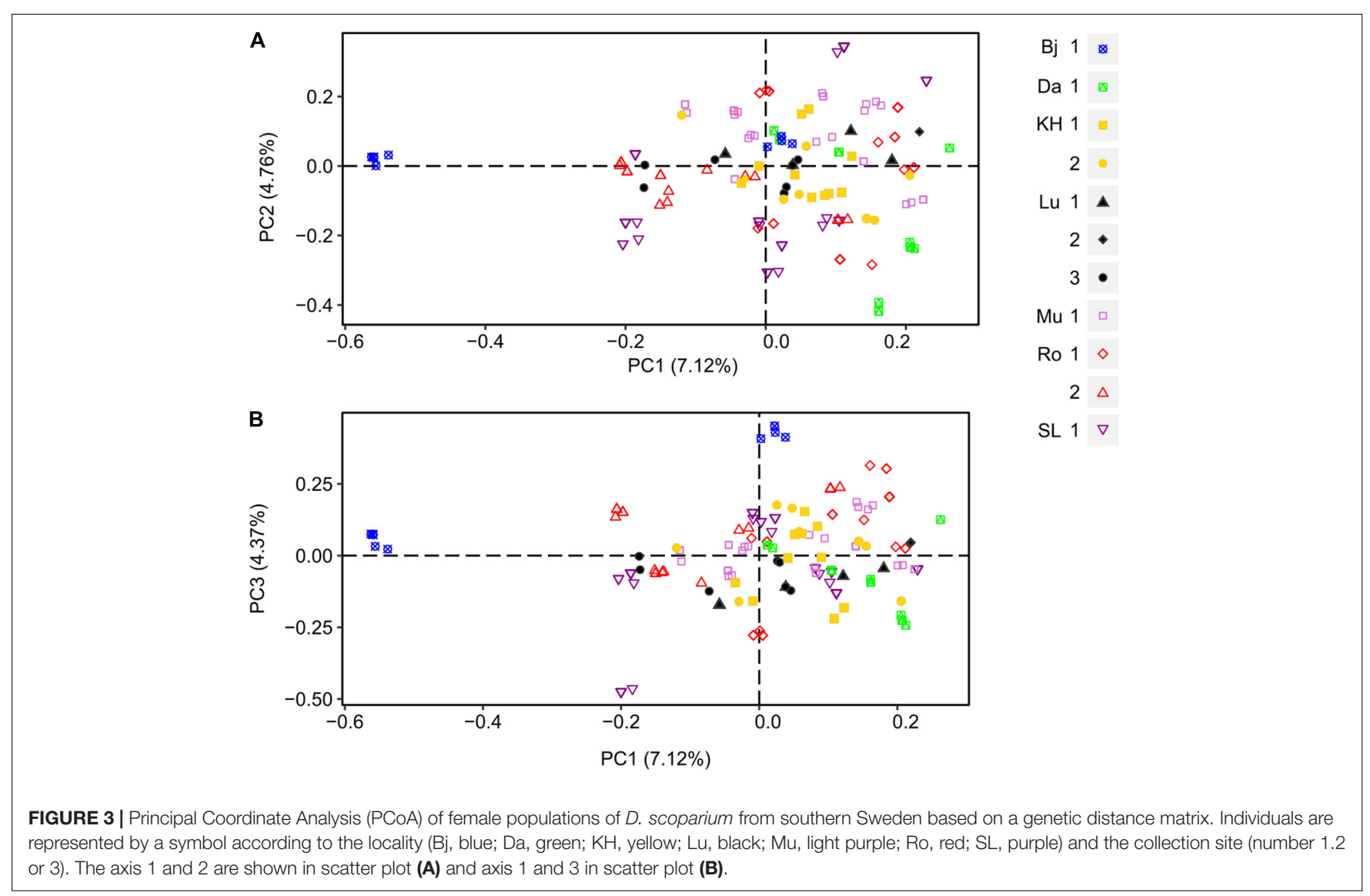

individual of different cushions. Additionally, two genotypes were shared between females and DMs, one genotype was shared between DM and NM and one genotype was shared between DM across localities (arrows in Figure 5). This last genotype was found in two individuals of population $\mathrm{Bj}$ and one of $\mathrm{Mu}$. Overall, there was no clear differentiation of the populations, apart from population $\mathrm{Bj}$. In this populations, $\mathrm{DM}$ genotypes were much closer to each other than to genotypes of other populations. Furthermore, one of the two female genotypes was shared among 20 individuals, sampled in two different cushions and both sexes.

\section{DISCUSSION}

In this study, we examined the genetic variability and structure of female and male populations of the facultatively nannandric moss Dicranum scoparium at different scales. Dwarf males and 

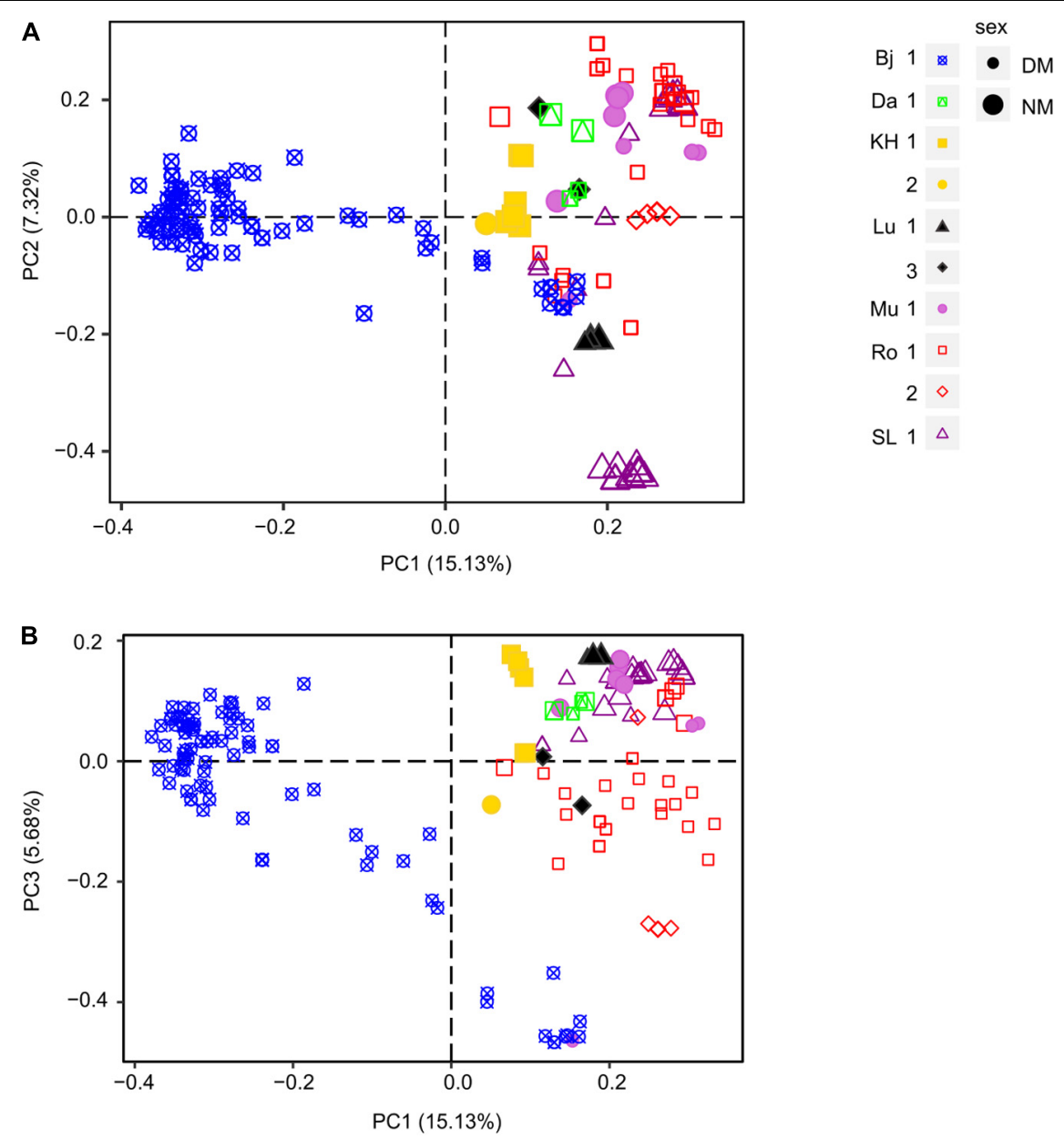

FIGURE 4 | Principal Coordinate Analysis (PCOA) of male populations of $D$. scoparium from southern Sweden based on a genetic distance matrix. Individuals are represented by a symbol (large, NM; small, DM) according to the locality (Bj, blue; Da, green; KH, yellow; Lu, black; Mu, light purple; Ro, red; SL, purple) and the collection site (number 1.2 or 3). The axis 1 and 2 are shown in scatter plot (A) and axis 1 and 3 in scatter plot (B).

normal-sized males often occurred together in a moss cushion. We showed that the overall levels of genetic diversity within females and dwarf males were relatively similar and much higher than among normal-sized males. The lower genetic diversity in NMs may therefore be a consequence of fewer haplotypes in the populations. Furthermore, clonality occurred in all three categories, yet at different degrees: level of clonality was high among NMs whereas it was much less so in females and DMs. Most of the genetic differentiation was partitioned within and among cushions and only a low fraction among localities. These results suggest that effective gene flow occurs regularly over long distances.

\section{Experimental Design}

Before we interpret the genetic diversity data, it is worth mentioning that (1) we have actively searched for loci that are variable and (2) that the regions are transcribed and therefore the SNP alleles are possibly under selection. This implies that absolute values of genetic diversity measures are not directly comparable with other studies, although our markers in several ways (representing expressed variation, point mutations) resemble allozyme markers, for which much of the population level studies were done in the past.

No reference genome for $D$. scoparium exists. Thus, designing a genetic diversity panel is challenging. Our approach, using RNA-seq and transcriptome assembly enables an affordable construction of transcribed portions of the genome that are likely evolutionarily relevant. Yet, the quality of such an assembly is highly dependent on the depth of sequencing, which is highly variable per transcript, and especially near the end of transcript. Furthermore, SNPs were identified using RNA-Seq reads aligned to the assembled transcriptome. This too is restricting and resulted in only 119 reliable SNPs. Then, due to the cost of RNASequencing, we used only 10 samples (one per locality) that would represent the total genetic diversity of each population. Hence, we selected variants that were relatively common and not entirely recurrent (in at least three and at most eight of the 10 samples). Furthermore, the extraction and genotyping steps themselves also lead to some losses. For example, DM for the populations in $\mathrm{Lu}$ were extracted but the genotyping was not successful. Finally, 


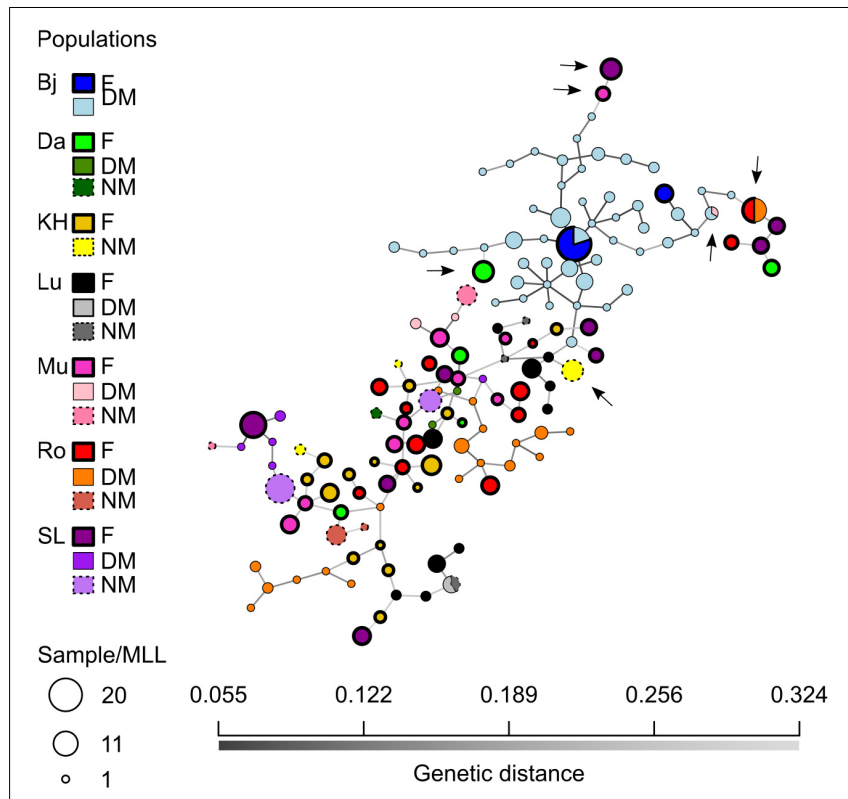

FIGURE 5 | Minimum-spanning network (MSN) of the Dicranum scoparium SNPs. Each node represent a unique multilocus lineage (or haplotype in our case). Colors represent sexes per localities and edges represent absolute genetic distance (Bj, blue; Da, green; $\mathrm{KH}$, yellow; Lu, black; Mu, pink; Ro, red; SL, purple; F, female; DM, dwarf-male and NM, normal-sized male).

SNP data pose new challenges when compared to other markers, because they potentially contain more missing data, error in SNP calling due to genotyping errors or other sources of inaccurate allele calls (Mastretta-Yanes et al., 2015). Having this in mind, we note that our data set produced clear results with respect to clonal diversity, gene diversity and genetic population structures for the whole material and when separated into NMs, DMs and females.

\section{Genetic Diversity and Population Structure}

Genetic diversity of females and all males taken together were similar, but NMs tended to be genetically less diverse relative to DMs, while females and DMs had comparable levels of genetic diversity. The PCoA, MSN, and AMOVA analyses showed weak genetic differentiation at larger scale, except for the locality Bjärsjölagård $(\mathrm{Bj})$. At locality levels genetic differentiation for females was particularly low $(\Phi=0.06)$, which is indicative of a high gene flow. The corresponding values for $H$. lutescens at locality level was around 0.10 (Rosengren et al., 2013) and 0.3 (Rosengren et al., 2015) from different regions in $S$ Sweden (Öland and Scania, respectively), suggesting a somewhat higher differentiation among those populations even though the sampling of $D$. scoparium spanned a larger geographic area. The difference between these two nannandric species could potentially be explained by the degree of isolation between populations and/or the fact that perennial, normal-sized males are much rarer in $H$. lutescens, increasing the risk for inbreeding due to son-mother fertilization with DMs.
A large fraction of the total variation in our study partitioned within cushions and among cushions within sites, suggesting that cushions in general have several genets which are notably dissimilar. This is particularly valid among DMs, where the fraction of the total variation residing within cushions reached $47 \%$. Our findings indicate that gene flow occurs between localities and that the relatively high levels of genetic diversity, both within females and males, are maintained through spore dispersal rather than vegetative fragment dispersal. The structure found in Dicranum populations are consistent with other moss studies that indicated limited population structure at larger scales but differentiation at cushion level (Cronberg, 2002; McDaniel and Shaw, 2005; Hutsemékers et al., 2010; Paasch et al., 2015; Désamoré et al., 2016). DMs and NMs often occurred simultaneously but the two types of males are obviously under different constraints and thereby contribute differently to the population dynamics. When present, dwarf males are often numerous and display a level of genetic diversity similar to the one of females. The proportion of DMs covaries positively with the haplotypic diversity of a population (at locality level), which is not the case for females and NMs. The vicinity of DMs to the female perichaetia is likely to be a great advantage in competition with NMs for fertilization, but NMs may be important for fertilization when conditions are unfavorable for DMs, as they are perennial and probably less sensitive to temporarily adverse climatic conditions. In this context is worth to notice that, if anything, the haplotypic and genetic diversity of DMs may be underestimated since a high number of the DMs were lost before DNA extraction.

The level of gene diversity found in D. scoparium is comparable to the dwarf males and females of the nannandric species H. lutescens (Rosengren et al., 2013, 2016). Although males were most likely dispersed locally, the authors showed that a fraction of males originated from more distant populations, hence maintaining high levels of genotypic diversity within cushions and across localities. In our study, we found NMs growing on soil, at the border of cushions, with generally much lower haplotypic diversity than DMs and females. This compares with results obtained for the non-nannandric species Syntrichia caninervis (Baughman et al., 2017), whose males displayed a lower genetic diversity than females. In both $H$. lutescens and $S$. caninervis, the differences in diversity within the male and female populations can be attributed to local environmental conditions such as moisture and temperature, which may affect spore dispersal and germination success (McDaniel et al., 2007; Rosengren and Cronberg, 2014; Rosengren et al., 2016; Baughman et al., 2017). Whereas several studies have demonstrated the positive association between moisture and presence of males (Tamm, 1964; Bowker et al., 2000; Sagmo Solli et al., 2000; Rosengren and Cronberg, 2014), the environmental constraints on NMs are largely unknown.

Finally, the haplotype networks provided some evidence of inbreeding events occurring in populations, especially at Ro and $\mathrm{Bj}$. Whereas extreme inbreeding indicative of repeated sonmother fertilizations was fairly frequently found in $H$. lutescens (Rosengren et al., 2016), only two haplotypes were shared between females and DMs in our study (Figure 5). However, 
the DM haplotypes were sometimes clustering tightly together with the female haplotype they were growing on as seen in the network analysis (Figure 4). Therefore, repeated son-mother fertilizations may occur in D. scoparium as well, but in general, external DM recruitment seems common enough to prevent extensive inbreeding.

\section{Clonal Diversity}

Although the scale of the sampling was not designed to elucidate the clonal structure of populations, we observed that the overall levels of clonality was low and that there was not much difference between the sexes, i.e., females and both types of males taken together. When separating the data set into DMs and NMs, it appears that the male clonality estimate is strongly influenced by DMs, lowering the index of association $\overline{\mathrm{r}}_{d}$. Indeed, we found a higher degree of clonality in NMs as compared to DMs and females, with $\overline{\mathrm{r}}_{d}$ values close to 1 (Table 3 ), suggesting more extensive clonal propagation for NMs and values closer to zero for DMs, indicating recombination. Previous studies on the perennial pleurocarps Hylocomium splendens and $H$. lutescens have brought out that populations often contains multiple, but few, genets in patches, suggesting that clonal expansion predominates over sexual recruitment (Cronberg et al., 2006b; Rosengren et al., 2013). Our results indicate that sexual reproduction in the studied populations more often results in recruitment of new female genets, also within female colonies. A high genotypic female diversity at patch level could possibly be explained by imperfect female control of spore germination, so that new normal-sized females sometimes are recruited along with the DMs. Rarer occurrence of NMs and their peripheral distribution in patches, indicate higher male mortality rates at recruitment and/or that female-dominated colonies forces male spores to become DMs and prevent them from escaping dwarfism by falling off the female, at least at the colony center. In order to better explain the control of development into NMs and DMs and associated patterns of genetic variability, further experimental studies are needed.

\section{Bjärsjölagård (Bj): The Rise of a New Population?}

The population of Bjärsjölagård (Bj) differs in several aspects; it is genetically divergent despite being geographically relatively close to sites $\mathrm{Lu}$ and $\mathrm{Da}$ (Figure 1). It probably represents a recent colonization event followed by external male recruitment, which may spread some light on genetic consequences of a founder event in a species with nannandry. The site is located in a former lime quarry, which is not a normal substrate for D. scoparium to occur, having preference for acidic soils at a $\mathrm{pH}$ around 3.27.1 (Tyler and Olsson, 2016). The previously open and barren calcareous ground has been partially covered by detritus from a scattered canopy of colonizing Fagus sylvatica, Corylus avellana, and Acer platanoides trees, allowing D. scoparium to establish together with species such as $H$. splendens in competition with more calciphilous species. At this locality, we found three isolated female cushions with sporophytes separated by maximum $1 \mathrm{~m}$. No NMs were found, but the population of DMs was the densest of our study, with up to 88 genotyped DMs (Table 2; pers. obs.). The haplotypic diversity of the total dataset (GAM) harbored at $\mathrm{Bj}$ was fairly similar to the one at Ro. Yet, gene diversity was the lowest of all the localities ( $\hat{h}=0.19$; Table 3 ). In further comparison to Ro, which had a similar number of females genotyped, we detected only two haplotypes within female populations. Consequently, they retained the lowest haplotype and gene diversity ( $G=1.57$ and $\hat{\mathrm{h}}=0.16$, respectively) as well the highest index of association $\left(\overline{\mathrm{r}}_{d}=0.97\right)$ among all female populations. These results indicate that vegetative growth of female cushions is predominant at this locality and are congruent with other moss species (Cronberg et al., 2006b; Rosengren et al., 2013; Baughman et al., 2017). Moreover, five female MLLs from other populations, namely from $\mathrm{Mu}, \mathrm{Lu}, \mathrm{Ro}, \mathrm{SL}$, and Da (arrows in Figure 5), were closer genetically to $\mathrm{DMs}$ of $\mathrm{Bj}$ than individuals of any other localities. Finally, two DMs shared the same MLL with one male from $\mathrm{Mu}$, making it the only MLL shared across localities. These results provide evidence that spores are dispersed over long distances and that male spores germinate more easily on female stems than on soil. Thus, even if the colonizing female population was not diverse, the DM male recruitment via spores results in quite extensive recombination events, which lead to an increase in genotypic diversity.

\section{Conclusion}

The genetic influence of dwarfism on population structure has rarely been studied and only few comparable studies exist. Here, we used SNP markers to investigate the genetic structure of seven populations of the facultatively nannandric species D. scoparium in Scania (Sweden) in a similar way as earlier done for the obligately nannandric species $H$. lutescens. The genetic differentiation at locality level was low indicating a strong gene flow. In the dense acrocarpous cushions of $D$. scoparium, the haplotypic diversity at patch level was higher for females (and NMs) than in the pleurocarpous and weft-forming H. lutescens, suggesting more frequent recruitment.

In D. scoparium, DMs and NMs often occurred together but the DMs were genotypically more frequent and divergent. The genotypic networks show that DM individuals at patch level represent both closely related haplotypes (suggesting inbreeding) and remotely related haplotypes (suggesting external gene flow). Nevertheless, NMs may regularly take part in fertilization as they are perennial and probably less sensitive to temporarily adverse climatic conditions. If so, the facultative nannandric system is prevented from transforming to obligate nannandry through sexual selection, contrasting to the nearly obligate or obligate nannandric conditions in $H$. lutescens and most Dicranum species.

Nannandry has probably developed to ensure fertilization and increase the number of male gamete donors. We see nannandry in mosses as a fertilization syndrome, a parallel to pollination syndromes in flowering plants, which ensure pollination and increases the available number of pollen donors. More studies on sexual reproduction and diversity in nannandric mosses are needed, especially in regards to facultative dwarfism. It would be particularly useful to determine the environmental condition 
for the recruitment and growth of normal-sized males to better understand their contribution to the population dynamics.

\section{DATA AVAILABILITY STATEMENT}

The raw dataset generated for this study can be found in the European Nucleotide Archive (https://www.ebi.ac.uk/ ena/) under accessions PRJEB37280 and ERP119316 (secondary study accession).

\section{AUTHOR CONTRIBUTIONS}

$\mathrm{AL}$ and NC wrote the text, conducted the sampling of the specimens, and participated in the interpretation of the results. TG and NC commented and critically reviewed the manuscript. $\mathrm{AL}$ conducted the laboratory work and the data analyses. TG designed the scripts specifically designed for SNP filtering. All authors approved the final manuscript.

\section{FUNDING}

This work was supported by the Royal Physiographic Society in Lund, Elly Olssons fund, Erik Philip-Sörensens Stiftelse,

\section{REFERENCES}

Agapow, P. M., and Burt, A. (2001). Indices of multilocus linkage disequilibrium. Mol. Ecol. Notes 1, 101-102. doi: 10.1046/j.1471-8278.2000.00014.x

Badyaev, A. V. (2002). Growing apart: an ontogenetic perspective on the evolution of sexual size dimorphism. Trends Ecol. Evol. 17, 369-378. doi: 10.1016/S01695347(02)02569-7

Baughman, J. T., Payton, A. C., Paasch, A. E., Fisher, K. M., and McDaniel, S. F. (2017). Multiple factors influence population sex ratios in the Mojave Desert moss Syntrichia caninervis. Am. J. Bot. 104, 733-742. doi: 10.3732/ajb. 1700045

Blanckenhorn, W. U., Preziosi, R. F., and Fairbairn, D. J. (1995). Time and energy constraints and the evolution of sexual size dimorphism - to eat or to mate. Evol. Ecol. 9, 369-381. doi: 10.1007/BF01237760

Bougeard, S., and Dray, S. (2018). Supervised multiblock analysis in R with the ade4 Package. J. Stat. Softw. 86, 1-17. doi: 10.18637/jss.v086.i01

Bowker, M. A., Stark, L. R., McLetchie, D. N., and Mishler, B. D. (2000). Sex expression, skewed sex ratios, and microhabitat distribution in the dioecious desert moss Syntrichia caninervis (Pottiaceae). Am. J. Bot. 87, 517-526. doi: $10.2307 / 2656595$

Chessel, D., Dufour, A. B., and Thioulouse, J. (2004). The ade4 package-I- Onetable methods. $R$ News $4,5-10$.

Cronberg, N. (2000). Genetic diversity of the epiphytic bryophyte Leucodon sciuroides in formerly glaciated versus nonglaciated parts of Europe. Heredity (Edinb) 84, 710-720. doi: 10.1046/j.1365-2540.2000.00719.x

Cronberg, N. (2002). Colonization dynamics of the clonal moss Hylocomium splendens on islands in a Baltic land uplift area: reproduction, genet distribution and genetic variation. J. Ecol. 90, 925-935. doi: 10.1046/j.1365-2745.2002. 00723.x

Cronberg, N., Natcheva, R., and Hedlund, K. (2006a). Microarthopods mediate sperm transfer in mosses. Science 313, 1255. doi: 10.1126/science.112 8707

Cronberg, N., Rydgren, K., and Okland, R. H. (2006b). Clonal structure and genetlevel sex ratios suggest different roles of vegetative and sexual reproduction in the clonal moss Hylocomium splendens. Ecography (Cop.) 29, 95-103. doi: 10.1111/j.2006.0906-7590.04361.x
Kungl. Vetenskapsakademien (BS2015-0084 to AL), and Sven och Lilly Lawskis fond.

\section{ACKNOWLEDGMENTS}

We would like to thank the DNA Sequencing Facility of the Department of Biology at Lund University for sequencing and extracting SNP markers and National Bioinformatics Infrastructure Sweden (NBIS) for their valuable help with bioinformatics. We sincerely thank the SNP\&SEQ Technology Platform in Uppsala (Science for Life Laboratory, Uppsala University) for genotyping the DNA samples. Finally, we would also like to thank Dr. Maria Mayol Martínez (CREAF Centre for Ecological Research and Forestry, Barcelona) for helpful discussion.

\section{SUPPLEMENTARY MATERIAL}

The Supplementary Material for this article can be found online at: https://www.frontiersin.org/articles/10.3389/fpls.2021. 517547/full\#supplementary-material

Crum, H. A., and Anderson, L. E. (1981). "Dicranum," in Mosses of eastern North America, Vol. 1, eds H. Crum, L. E. Anderson, and L. Anderson (New York: Columbia University Press), 151-217.

Désamoré, A., Patiño, J., Mardulyn, P., Mcdaniel, S. F., Zanatta, F., Laenen, B., et al. (2016). High migration rates shape the postglacial history of amphi-Atlantic bryophytes. Mol. Ecol. 25, 5568-5584. doi: 10.1111/mec.13839

Dray, S., and Dufour, A. B. (2007). The ade4 package: implementing the duality diagram for ecologists. J. Stat. Softw. 22, 1-20.

Dray, S., Dufour, A. B., and Chessel, D. (2007). The ade4 package-II: two-table and K-table methods. $R$ News 7, 47-52.

Eriksson, O. (1989). Seedling dynamics and life histories of clonal plants. Oikos 55, 231-238. doi: 10.2307/3565427

Eriksson, O. (1993). Dynamics of genets in clonal plants. Trends Ecol. Evol. 8, 313-316. doi: 10.1016/0169-5347(93)90237-j

Excoffier, L., Smouse, P. E., and Quattro, J. M. (1992). Analysis of molecular variance inferred from metric distances among DNA haplotypes: application to human mitochondrial DNA restriction data. Genetics 131, 479-491. doi: 10.1093/genetics/131.2.479

Fairbairn, D. J., Blanckenhorn, W. U., and Székely, T. (2007). Sex, Size and Gender Roles: Evolutionary Studies of Sexual Size Dimorphism. New York, NY: Oxford University Press.

Frey, W., and Kürschner, H. (2011). Asexual reproduction, habitat colonization and habitat maintenance in bryophytes. Flora Morphol. Distrib. Funct. Ecol. Plants 206, 173-184. doi: 10.1016/j.flora.2010.04.020

Gabriel, S., Ziaugra, L., and Tabbaa, D. (2009). SNP genotyping using the Sequenom MassARRAY iPLEX platform. Curr. Protoc. Hum. Genet. 60, 2.12.1-2.12.18.

Geber, M. A., Dawson, T. E., and Delph, L. F. (1999). in Gender and Sexual Dimorphism in Flowering Plants, eds M. A. Geber, T. E. Dawson, and L. F. Delph (Berlin: Springer Verlag). doi: 10.1007/978-3-662-03908-3

Glime, J. M. (2007). Bryophyte Ecology: Physiological Ecology, Vol. 1. Houghton, MI: EBook sponsored by Michigan Technological University and the International Association of Bryologists.

Glime, J. M., and Bisang, I. (2017). "Sexuality: size and sex differences," in Bryophyte Ecology: Physiological Ecology, Vol. 1, ed. J. M. Glime (Houghton, MI: Ebook sponsored by Michigan Technological University and the International Association of Bryologists). 
Grabherr, M. G., Haas, B. J., Yassour, M., Levin, J. Z., Thompson, D. a., Amit, I., et al. (2011). Full-length transcriptome assembly from RNA-Seq data without a reference genome. Nat. Biotechnol. 29, 644-652. doi: 10.1038/nbt.1883

Grünwald, N. J., and Hoheisel, G.-A. (2006). Hierarchical analysis of diversity, selfing, and genetic differentiation in populations of the oomycete Aphanomyces euteiches. Phytopathology 96, 1134-1141. doi: 10.1094/PHYTO-96-1134

Grünwald, N. J., Kamvar, Z. N., Everhart, S. E., Tabima, J. F., and Knaus, B. J. (2017). Population Genetics and Genomics in R. Available online at: http://grunwaldlab. github.io/Population_Genetics_in_R/ (accessed March 17, 2021).

Haas, B. J., Papanicolaou, A., Yassour, M., Grabherr, M., Blood, P. D., Bowden, J., et al. (2013). De novo transcript sequence reconstruction from RNA-seq using the Trinity platform for reference generation and analysis. Nat. Protoc. 8, 1494-1512. doi: 10.1038/nprot.2013.084

Hedenäs, L., and Bisang, I. (2004). Key to European Dicranum species. Herzogia $17,179-197$

Hedenäs, L., and Bisang, I. (2011). The overlooked dwarf males in mossesUnique among green land plants. Perspect. Plant Ecol. Evol. Syst. 13, 121-135. doi: 10.1016/j.ppees.2011.03.001

Hutsemékers, V., Hardy, O. J., Mardulyn, P., Shaw, A. J., and Vanderpoorten, A. (2010). Macroecological patterns of genetic structure and diversity in the aquatic moss Platyhypnidium riparioides. New Phytol. 185, 852-864. doi: 10. $1111 /$ j.1469-8137.2009.03094.x

Ireland, R. R. (2007). "Dicranum (Family Dicranaceae)," in Flora of North America, ed. R. H. Zander (New York, NY: Oxford University Press), 397-420.

Isaac, J. L. (2005). Potential causes and life-historis consequences of sexual size dimorphism in mammals. Mamm. Rev. 35, 101-115. doi: 10.1111/j.1365-2907. 2005.00045.x

Jombart, T. (2008). adegenet: a R package for the multivariate analysis of genetic markers. Bioinformatics 24, 1403-1405. doi: 10.1093/bioinformatics/btn129

Jombart, T., and Ahmed, I. (2011). adegenet 1.3-1: new tools for the analysis of genome-wide SNP data. Bioinformatics 27, 3070-3071. doi: 10.1093/ bioinformatics/btr521

Kamvar, Z. N., Brooks, J. C., and Grünwald, N. J. (2015). Novel R tools for analysis of genome-wide population genetic data with emphasis on clonality. Front. Genet. 6:208. doi: 10.3389/fgene.2015.00208

Kamvar, Z. N., Tabima, J. F., and Grünwald, N. J. (2014). Poppr: an R package for genetic analysis of populations with clonal, partially clonal, and/or sexual reproduction. PeerJ 2:e281. doi: 10.7717/peerj.281

Laaka-Lindberg, S., Korpelainen, H., and Pohjamo, M. (2003). Dispersal of asexual propagules in bryophytes. J. Hattori Bot. Lab. 192, 319-330.

Lang, A. S., Kruijer, J. D., and Stech, M. (2014). DNA barcoding of arctic bryophytes- an example from the moss genus Dicranum (Dicranaceae, Bryophyta). Polar Biol. 37, 1157-1169. doi: 10.1007/s00300-014-1509-7

Langmead, B., Trapnell, C., Pop, M., and Salzberg, S. L. (2009). Ultrafast and memory-efficient alignment of short DNA sequences to the human genome. Genome Biol. 10:R25. doi: 10.1186/gb-2009-10-3-r25

Levins, R. (1969). Some demographic and genetic consequences of environmental heterogeneity for biological control. Bull. Entomol. Soc. Am. 15, 237-240. doi: 10.1093/besa/15.3.237

Li, H., Handsaker, B., Wysoker, A., Fennell, T., Ruan, J., Homer, N., et al. (2009). The sequence alignment/map format and SAMtools. Bioinformatics 25, 20782079. doi: 10.1093/bioinformatics/btp352

Mastretta-Yanes, A., Arrigo, N., Alvarez, N., Jorgensen, T. H., Piñero, D., and Emerson, B. C. (2015). Restriction site-associated DNA sequencing, genotyping error estimation and de novo assembly optimization for population genetic inference. Mol. Ecol. Resour. 15, 28-41. doi: 10.1111/1755-0998. 12291

McDaniel, S. F., and Shaw, A. J. (2005). Selective sweeps and intercontinental migrations in the cosmopolitan moss Ceratodon purpureus (Hedw.) Brid. Mol. Ecol. 14, 1121-1132. doi: 10.1111/j.1365-294x.2005.02484.x

McDaniel, S. F., Willis, J. H., and Shaw, A. J. (2007). A linkage map reveals a complex basis for segregation distortion in an interpopulation cross in the moss Ceratodon purpureus. Genetics 176, 2489-2500. doi: 10.1534/genetics.107. 075424

McElligott, A. G., Gammell, M. P., Harty, H. C., Paini, D. R., Murphy, D. T., Walsh, J. T., et al. (2001). Sexual size dimorphism in fallow deer (Dama dama): do larger, heavier males gain greater mating success? Behav. Ecol. Sociobiol. 49, 266-272. doi: 10.1007/s002650000293
Mishler, B. D. (1988). "Reproductive ecology of bryophytes," in Plant Reproductive Biology. Patterns and Strategies, eds J. L. Doust and L. L. Doust (Oxford: Oxford University Press), 285-306.

Moya-Laraño, J., Halaj, J., and Wise, D. H. (2002). Climbing to reach females: romeo should be small. Evolution (N. Y) 56, 420-425. doi: 10.1554/00143820(2002)056[0420:ctrfrs]2.0.co;2

Paasch, A. E., Mishler, B. D., Nosratinia, S., Stark, L. R., and Fisher, K. M. (2015). Decoupling of sexual reproduction and genetic diversity in the femalebiased mojave desert moss Syntrichia caninervis (Pottiaceae). Int. J. Plant Sci. 176, 751-761. doi: 10.1086/682708

Patiño, J., and Vanderpoorten, A. (2018). Bryophyte biogeography. CRC Crit. Rev. Plant Sci. 37, 175-209. doi: 10.1080/07352689.2018.1482444

Pichonet, A., and Gradstein, S. R. (2012). Male dwarfism in the genus Dicranum (Dicranaceae)-a review. Cryptogam. Bryol. 33, 299-311. doi: 10.7872/cryb.v33. iss3.2012.299

Pietsch, T. W. (2005). Dimorphism, parasitism, and sex revisited: modes of reproduction among deep-sea ceratioid anglerfishes (Teleostei: Lophiiformes). Ichthyol. Res. 52, 207-236. doi: 10.1007/s10228-005-0286-2

Poissant, J., Wilson, A. J., and Coltman, D. W. (2010). Sex-specific genetic variance and the evolution of sexual dimorphism: a systematic review of cross-sex genetic correlations. Evolution (N. Y) 64, 97-107. doi: 10.1111/j.1558-5646. 2009.00793.x

Puixeu, G., Pickup, M., Field, D. L., and Barrett, S. C. H. (2019). Variation in sexual dimorphism in a wind-pollinated plant: the influence of geographical context and life-cycle dynamics. New Phytol. 224, 1108-1120. doi: 10.1111/nph. 16050

R Development Core Team (2013). R: A Language and Environment for Statistical Computing. Available online at: http://www.r-project.org/ (accessed March 17, 2021).

Rosengren, F., and Cronberg, N. (2014). The adaptive background of nannandry: dwarf male distribution and fertilization in the moss Homalothecium lutescens. Biol. J. Linn. Soc. 113, 74-84. doi: 10.1111/bij.12332

Rosengren, F., Cronberg, N., and Hansson, B. (2016). Balance between inbreeding and outcrossing in a nannandrous species, the moss Homalothecium lutescens. Heredity (Edinb) 116, 107-113. doi: 10.1038/hdy.2015.79

Rosengren, F., Cronberg, N., Reitalu, T., and Prentice, H. C. (2013). Genetic variation in the moss Homalothecium lutescens in relation to habitat age and structure. Botany 91, 431-441. doi: 10.1139/cjb-2012-0258

Rosengren, F., Hansson, B., and Cronberg, N. (2015). Population structure and genetic diversity in the nannandrous moss Homalothecium lutescens: does the dwarf male system facilitate gene flow? BMC Evol. Biol. 15:12. doi: 10.1186/ s12862-015-0545-4

Ross, P., Hall, L., Smirnov, I., and Haff, L. (1998). High level multiplex genotyping by MALDI- TOF mass spectrometry. Nat. Biotechnol. 16, 1347-1351. doi: $10.1038 / 4328$

Rouse, G. W., Wilson, N. G., Worsaae, K., and Vrijenhoek, R. C. (2015). Report a dwarf male reversal in bone-eating worms. Curr. Biol. 25, 236-241. doi: 10.1016/j.cub.2014.11.032

Rudolph, H., Kirchhoff, M., and Gliesmann, S. (1988). "Sphagnum culture techniques," in Proceedings of the Bryological Methods Workshop, Mainz, ed. J. M. Glime (Nichinan: Hattori Botanical Laboratory), 25-34.

Rydgren, K., Cronberg, N., and Økland, R. H. (2006). Factors influencing reproductive success in the clonal moss, Hylocomium splendens. Oecologia 147, 445-454. doi: 10.1007/s00442-005-0290-2

Sagmo Solli, I. M., Söderström, L., Bakken, S., Flatberg, K. I., and Pedersen, B. (2000). Studies of fertility of Dicranum majus in two populations with contrasted sporophyte production. J. Bryol. 22, 3-8. doi: 10.1179/jbr.2000. 22.1 .3

Stoddart, J. A., and Taylor, J. F. (1988). Genotypic diversity: estimation and prediction in samples. Genetics 118, 705-711. doi: 10.1093/genetics/118.4.705

Storm, N., Darnhofer-Patel, B., van den Boom, D., and Rodi, C. P. (2003). MALDI-TOF mass spectrometry based SNP genotyping. Methods Mol. Biol. 212, 241-262. doi: 10.1385/1-59259-327-5:241

Tamm, C. O. (1964). Growth of Hylocomium splendens in relation to tree canopy. Bryologist 67, 423-426. doi: 10.2307/3240767

Tyler, T., and Olsson, P. A. (2016). Substrate pH ranges of south Swedish bryophytes-Identifying critical $\mathrm{pH}$ values and richness patterns. Flora Morphol. Distrib. Funct. Ecol. Plants 223, 74-82. doi: 10.1016/j.flora.2016.05.006 
Vamosi, J. C., Otto, S. P., and Barrett, S. C. H. (2003). Phylogenetic analysis of the ecological correlates of dioecy in angiosperms. J. Evol. Biol. 16, 1006-1018. doi: 10.1046/j.1420-9101.2003.00559.x

Vanderpoorten, A., and Goffinet, B. (2009). Introduction to Bryophytes. Cambridge: Cambridge University Press.

Vollrath, F. (1998). Dwarf males. Trends Ecol. Evol. 13, 159-163. doi: 10.1016/ s0169-5347(97)01283-4

Vrijenhoek, R. C., Johnson, S. B., and Rouse, G. W. (2008). Bone-eating Osedax females and their "harems" of dwarf males are recruited from a common larval pool. Mol. Ecol. 17, 4535-4544. doi: 10.1111/j.1365-294X.2008.03937.x
Conflict of Interest: The authors declare that the research was conducted in the absence of any commercial or financial relationships that could be construed as a potential conflict of interest.

Copyright (c) 2021 Lang, Gehrmann and Cronberg. This is an open-access article distributed under the terms of the Creative Commons Attribution License (CC BY). The use, distribution or reproduction in other forums is permitted, provided the original author(s) and the copyright owner(s) are credited and that the original publication in this journal is cited, in accordance with accepted academic practice. No use, distribution or reproduction is permitted which does not comply with these terms. 